\title{
Intelligent PID Controller Tuning for Higher Order Process System
}

\author{
Haider Ali and Sulochana Wadhwani \\ Faculty, Dept of Electrical Engineering, MITS, Gwalior, MP, India \\ haidermtr@gmail.com
}

\begin{abstract}
This paper demonstrates the implementation of PID controller tuning using evolutionary technique which is Genetic Algorithm (GA). The optimal PID control scheme is applied to higher order system. The execution of this evolutionary strategy is evaluated by setting the objective function as mean square error (MSE), Integral time absolute error (ITAE) and Integral absolute error (IAE) one at a time. This technique will determine the global minimum value of its objective function and hence gives the optimal value of the gain parameters. The PID controller performance analysis using ZieglerNichols Tuning methodology and Genetic Algorithm is also demonstrated in this paper.
\end{abstract}

Keywords: Genetic Algorithm, PID Controller, Ziegler-Nichols strategy

\section{Introduction}

PID is a remarkable control strategy, widely most applied and used in process industries such as crude oil and gas, chemical, petrochemical and paper, beverage, etc to manipulate and control the overall process variables. It has already been shown and tested in terms of reliability and robustness in controlling process variables ranging from pressure, ${ }_{\mathrm{p}} \mathrm{H}$ temperature, level, flow etc. Because of having low cost, easy to preserve, as well as straightforwardness in control structure and easy to understand, these could be other factors that attracted the industries to choose PID controller. However, If the Tuning of PID controller is improper then It could lead to cyclic and slow convalescence, poor robustness and the worst case scenario will be the collapse of whole system operation [1]. This problem leads the researchers to find the best method to determine the best PID parameters gain values.

Many schemes have already been proposed since the introduction of PID controller to find the optimum gain parameters of PID controller. Ziegler-Nichols [2] and Cohen-Coon [3] are amongst the best and pioneer strategies in PID controller tuning. They have proposed many experimental PID tuning methods based on trails and errors methodology and also the process reaction curves on which Cohen-Coon method is grounded. However difficulties may arise in tuning the PID controller because of containing higher order systems, delayed systems, non-minimum phase systems and non-linear process along with PID controller. For examples, Cohen-Coon method is entirely valid in cases with unit response of the system is S-shaped[4] and on the other hand Ziegler-Nichols method will give rise to high overshoot, high oscillation, and longer settling time for the higher order systems[5]. Different types of methods are utilized or employed to overcome these difficulties which includes traditional methods or conventional methods such as ZieglerNichols [6] and pole placement methods and also implementation of modern heuristic optimization techniques such as genetic algorithms, particle swarm optimization neural network, fuzzy logic, and population based incremental learning. Heuristic optimization not only renders the best tuning parameters but also shows how close to optimally a particular feasible solution is [9]. It is a best practice of exploring a solution at practical computational cost. Recently, optimization techniques have been extensively practiced 
and applied by many researchers for optimal PID parameters due to its high potential of evaluating the best solution. [10] has proposed the advanced GA method to tune PID for optimal control of RO plant with minimum rise time, minimum overshoot and fast settling time. [11] has lucratively utilized Genetic Algorithm to tune the PID controller for lower damping and slow response of plants. Mohammad Zain et al. [12] have applied the Genetic Algorithm to tune PID controller to receive optimum value of parameters to control the single-link flexible manipulator in vertical motion. Genetic Algorithm is a multiple point global search optimization technique. The proposed methodologies is verified by taking example of higher order system with performance index to fix the error in the system

$$
\begin{gathered}
\mathrm{MSE}=\frac{1}{n} \sum_{i=1}^{n}(e(t))^{2} d t \\
\mathrm{ITAE}=\int_{0}^{T} t|e(t)| d t \\
\mathrm{IAE}=\int_{0}^{\infty}|e(t)| d t
\end{gathered}
$$

\section{PID Controller}

The PID controller determines the values of controlled variables, compare the actual value to the desired value (reference), computes the deviation and produces a control signal that will melt off the deviation to zero or to a smallest possible value. The method by which the PID controller produces the command signal is called mode of control or control action. PID controller is a combination of three controller actions namely proportional controller, derivative controller and the integral controller. These are denoted by $\mathrm{k}_{\mathrm{p}}, \mathrm{k}_{\mathrm{d}}$ and $\mathrm{k}_{\mathrm{i}}$. Values of these parameters will improve the overall steady state as well as transient response of the system i.e. settling time, reduce overshoot, rise time, steady state error.

Transfer function of PID controller is shown below:

$$
\mathrm{C}(\mathrm{s})=\frac{U(s)}{E(s)}=\mathrm{k}_{\mathrm{p}}+\frac{k i}{s}+\mathrm{k}_{\mathrm{d}} \mathrm{s}
$$

Block diagram of a general PID controller is demonstrated in Fig.1 given below. Input to this controller is error signal which is the remainder of set value and actual value, actuates the PID controller with the resulting signal weighted and summed to form the control signal U(s), to control the plant. We will get the new control signal and again new error signal will be computed. Then new control signal will be sent to the plant incessantly until the steady state error melt off to $2 \%$ to $5 \%$.

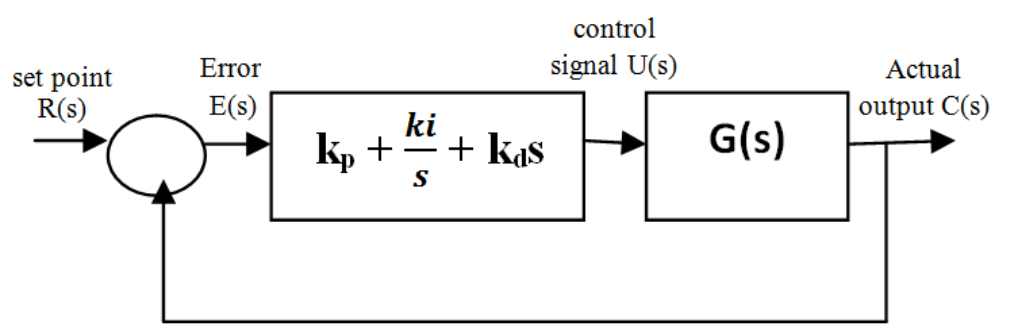

Figure 1. PID Controller Representation

\section{Methodology}

\section{A. Ziegler-Nichols Method}

Ziegler-Nichols scheme for PID controller tuning is the classical method which is widely practiced for designing several controllers. Ziegler and Nichols confronted two 
methods of designing a controller, one is step response method and another one is frequency response method.

\section{B. Implementation of ZN-PID Controller}

In this scheme integral time $\mathrm{T}_{\mathrm{i}}$ will be specified to infinity $(\infty)$ and derivative time will be specified to the zero (0). This is done to set out the initial setting of the system. After putting all these parameter values we can achieve the proportional controller gain. Incrementing the value of proportional gain until the point of instability is achieved i.e. sustained oscillation occurs, we will obtain the critical gain value $\mathrm{K}_{\mathrm{c}}$. Thereafter we need to compute the frequency of oscillation, we can find with the help of Routh-Hurwitz stability criterion $T_{c}$. Further the values of PID controller gains $K_{d}, K_{i}, K_{p}$ can be computed with the help ZN-Table given below:

In this study, Transfer function used to assess the performance between the GA and Ziegler-Nichols for higher order system $\mathrm{G}_{1}(\mathrm{~s})$ is shown.

$$
\mathrm{G}_{1}(\mathrm{~s})=\frac{(1)}{s(s+1)(s+5)}
$$

Table 1. ZN- PID Tuning Parameter

\begin{tabular}{|l|l|l|l|}
\hline Controller & $\mathrm{K}_{\mathrm{p}}$ & $\mathrm{T}_{\mathrm{i}}$ & $\mathrm{T}_{\mathrm{d}}$ \\
\hline $\mathrm{P}$ & $0.5 \mathrm{~K}_{\mathrm{c}}$ & $\infty$ & 0 \\
\hline $\mathrm{PI}$ & $0.45 \mathrm{~K}_{\mathrm{c}}$ & $0.8333 \mathrm{~T}_{\mathrm{c}}$ & 0 \\
\hline PID & $0.6 \mathrm{~K}_{\mathrm{c}}$ & $0.5 \mathrm{~T}_{\mathrm{c}}$ & $0.125 \mathrm{~T}_{\mathrm{c}}$ \\
\hline
\end{tabular}

\section{Genetic Algorithms}

\section{Overview}

The idea of evolutionary computing was innovated in 1960 by I.Rechenberg in his work Evolutionary strategy. Genetic algorithms are computerized search and optimization algorithms grounded on the mechanics of natural genetics and natural selection. Prof. Holland of university Michigan, projected the concept of these algorithms in the midsixties and brought out his seminal work. Genetic algorithm are advantageous at taking a larger, potentially vast, search spaces and navigating them looking for optimal compounding of things and results which we might not find ever. GA starts with multiple points which contain number of chromosomes where each of the chromosomes represents a solution to a problem and its functioning is appraised based on some fitness function. Grounded on its fitness value, parent chromosomes are selected to undergo three natural stages i.e. selection, crossover, and mutation. Steps to be followed given below.

\section{GA based PID Controller Tuning}

\subsection{GA Tuning Parameters}

Block diagram of GA-PID is shown in Figure 2 and flow chart is shown in Figure3.The values in Table 3 describe the initial settings utilized for this work.

Table 2. GA Initialization

\begin{tabular}{|c|c|}
\hline Parameters & Values \\
\hline Lower bound $\left[\mathrm{K}_{\mathrm{p}}, \mathrm{K}_{\mathrm{i}}, \mathrm{K}_{\mathrm{d}}\right]$ & {$\left[\begin{array}{ll}1 & 1\end{array}\right]$} \\
\hline Upper bound $\left[\mathrm{K}_{\mathrm{p}}, \mathrm{K}_{\mathrm{i}}, \mathrm{K}_{\mathrm{d}}\right]$ & {$[505050]$} \\
\hline Stopping criterion(iterations) & 50 \\
\hline
\end{tabular}




\begin{tabular}{|c|c|}
\hline Population Size & 20 \\
\hline Crossover Fraction & 4 \\
\hline Mutation Fraction & 0.06 \\
\hline
\end{tabular}

\subsection{Implementation of GA-PID Cotroller Optimization}

Step 1. Create initial population $\mathrm{P}(\mathrm{t})$.

Step 2. Assess the fitness of each chromosome or string in population $\mathrm{P}(\mathrm{t})$. Assess the fitness function which can be the inverse of error function.

Step 3. Pick out the best fit solution. Choose $\mathrm{P}(\mathrm{t}+1)$ from population according to their fitness value.

Step 4. Apply crossover to selected member pairs and mate individuals in $\mathrm{P}(\mathrm{t}+1)$ as parents to beget new off springs.

Step 5. Apply mutation by slightly altering some random solution.

Step 6. Step 2-5 are iterated until the number of iterations has been accomplished and note down the optimized $\mathrm{K}_{\mathrm{i}}, \mathrm{K}_{\mathrm{p}}, \mathrm{K}_{\mathrm{d}}$, values.

Step 7. Now execute the closed loop operation with GA-PID and plant system and compute the time domain specification for the system.

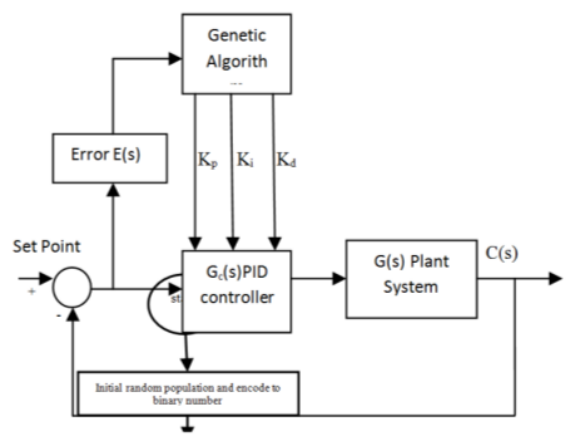

Figure 2. Block Diagram for GA-PID controller

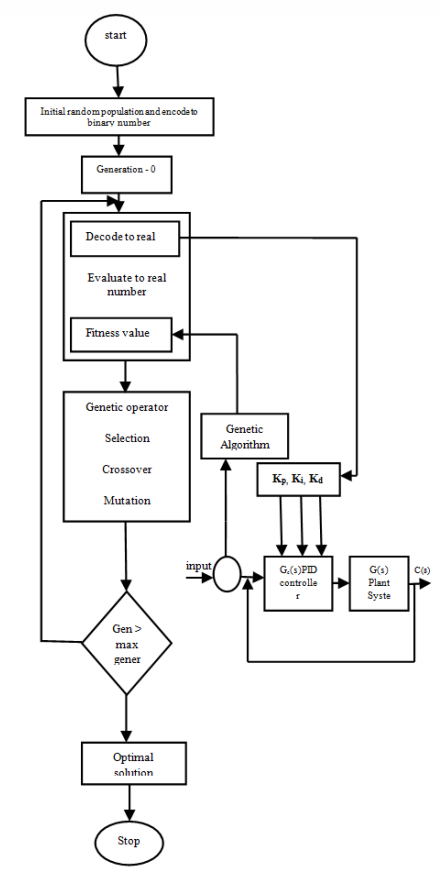

Figure 3. Flow Chart of Genetic Algorithm for PID Tuning 


\section{Results}

If after satisfying the minimum value of the objective function, the values of gain parameters are within the pre-defined limits then, we will the stop the optimization process and use current values of $\mathrm{K}_{\mathrm{p}}, \mathrm{K}_{\mathrm{i}}, \mathrm{K}_{\mathrm{d}}$ for further process, otherwise continue the operation till the stopping criteria for error is met. Fig5 Depict the optimized values of $\mathrm{K}_{\mathrm{p}}$, $\mathrm{K}_{\mathrm{i}}, \mathrm{K}_{\mathrm{d}}$ for different iterations.

The outcome for closed-loop step response of the system with ZN-PID and GA-PID are indicated in Figures 6(a) \&(b) respectively. It can be easily observed that the step response with GA-PID is better than response with ZN-PID. Details of these outcomes are given in Table 5. The values of rise time, maximum overshoot, settling time, MSE, ITAE, IAE between GA and $\mathrm{ZN}$ are dissimilar from each other. GA tuning strategy gives better response compared to $\mathrm{ZN}$ tuning strategy. Now we can easily say after looking at Table 5 that ZN-Tuned PID system has inadequate rise time, poor settling time, higher overshoot. In this case of higher system, ITAE, MSE, IAE are nearly same when GA-PID is used to control the system as shown in Figure 6(b). However, GA optimized by IAE gives the more estimable settling time and overshoot which is nearly 12 seconds faster and $14 \%$ reduction with respect to GA optimized by MSE and ITAE. Although GA optimized by IAE offered by settling time and overshoot compared with GA optimized by ITAE, both give superior performance than $\mathrm{ZN}$-Tuning method.

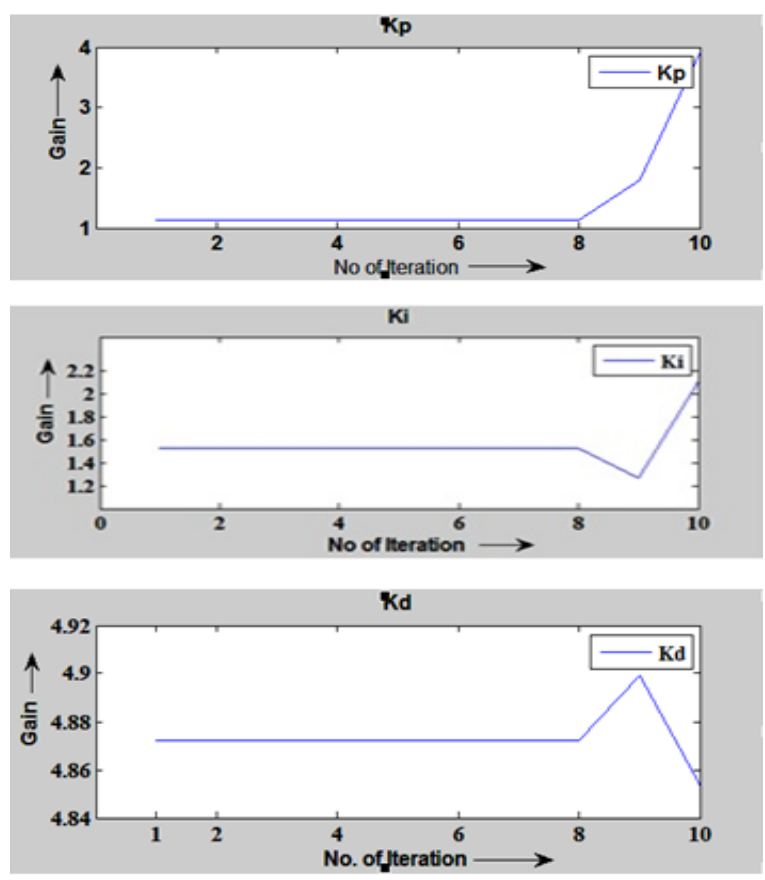

Figure 5. Optimized Values of $\left[K_{p}, K_{i}, K_{d}\right]$ for Different Iterations.

Table 5. Comparison Performance for Higher Order System

\begin{tabular}{|c|c|c|c|c|}
\hline & ZN & $\begin{array}{c}\text { GA } \\
\text { (MSE) }\end{array}$ & $\begin{array}{c}\text { GA } \\
\text { (IAE) }\end{array}$ & $\begin{array}{c}\text { GA } \\
\text { (ITAE) }\end{array}$ \\
\hline MSE & - & 0.032 & - & - \\
\hline IAE & - & - & 0.45 & - \\
\hline ITAE & - & - & - & 0.324 \\
\hline Rise time & 7.21 & 0.3084 & 0.2536 & 0.3526 \\
\hline $\begin{array}{c}\text { Settling } \\
\text { time }\end{array}$ & 13.06 & 2.9547 & 2.978 & 2.9921 \\
\hline
\end{tabular}




\begin{tabular}{|c|c|c|c|c|}
\hline $\begin{array}{c}\text { overshoo } \\
\mathbf{t}\end{array}$ & $\begin{array}{c}57.40 . \\
62\end{array}$ & 32.85 & 29.55 & 28.22 \\
\hline $\mathbf{K}_{\mathbf{p}}$ & 6.32 & 49.17 & 46.35 & 45.38 \\
\hline $\mathbf{K}_{\mathbf{i}}$ & 17.99 & 23.99 & 25.32 & 26.02 \\
\hline $\mathbf{K}_{\mathbf{d}}$ & 12.80 & 20.12 & 20.32 & 22.30 \\
\hline
\end{tabular}

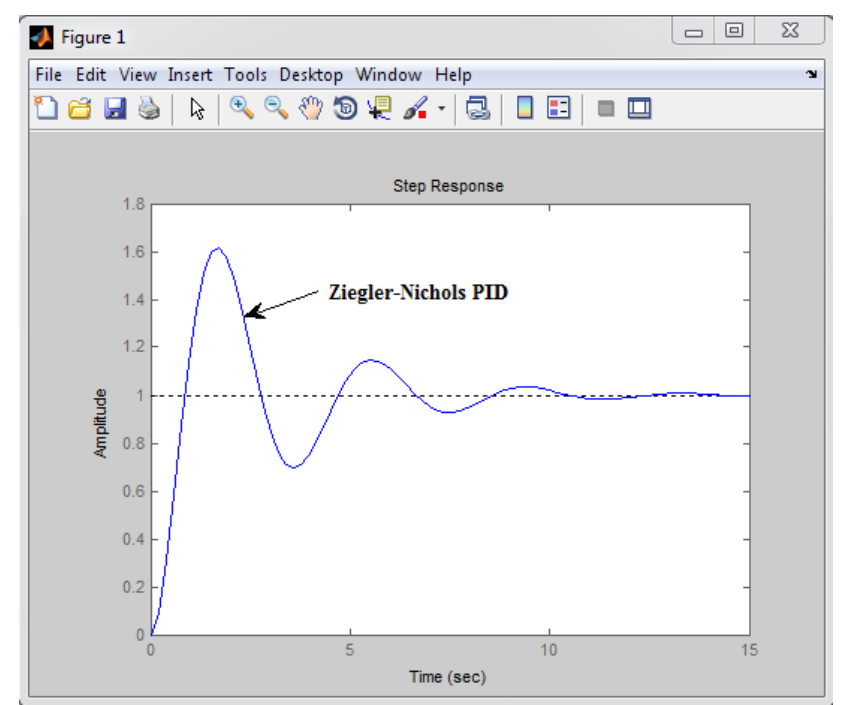

Figure 6. (a) Step Response with ZN-PID

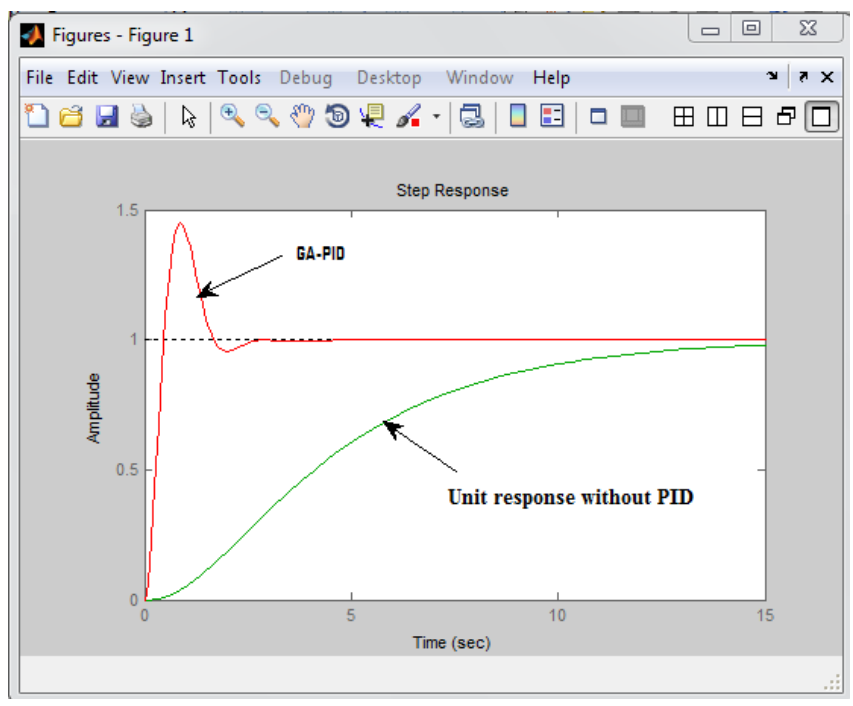

Fig. 6(b) Step response with GA-PID

\section{Conclusions}

PID controller has been tuned using $\mathrm{ZN}$ method, and innovative heuristic method GA grounded for higher order system. GA optimized by MSE and ITAE however IAE yield more salutary performance with the regards to the trade-off between settling time, maximum overshoot, rise time and undershoot for higher order system. In the terms of reliability GA proposes consistency in attaining its globally minimum fitness value of the objective function that is ITAE and IAE. The values of rise time, settling time, maximum overshoot, MSE, ITAE, IAE between GA and ZN are nearly different from each other. GA tuning strategy contributes better response compared to ZN-Tuning method. 


\section{References}

[1] K. J. Astrom and T. Hagglund, Automatic Tuning of PID Controllers. 1988: Instrument Society of America.

[2] J. G. Ziegler and N.B. Nichols, Optimum Settings for Automatic Controllers. Trans. ASME. 64(8): p. 759-768, 1942.

[3] G. H. Cohen and G. A. Coon, Theoretical Consideration of Retarded Control. Trans. ASME. 75: p. 827834, 1953.

[4] G. Saravanakumar, R.S.D. Wahidhabanu, and V.I. George, Robustness and Performance of Modified Smith Predictors for Processes with Longer Dead-Times. International Journal on Automatic Control and System Engineering. 6(3), 2006.

[5] T. Jain and M.J. Nigam, Optimisation of PD-PI Controller Using Swarm Intelligence. Journal of Theoretical and Applied Information Technology,

[6] 4(11): p. 1013-1018, 2008.

[7] K. J. Astrom, Automatic Tuning and Adaptation for PID Controllers - a Survey. Control Engineering Practice. 1(4): p. 699-714, 1993.

[8] K. J. Astrom and T. Hagglund, PID Controllers: Theory, Design, and Tuning. 1995: Instruments Society of America.

[9] P. B. De Moura Oliveira, Modern Heuristics Review for PID Control Optimization: a Teaching Experiment. in Proceeding of International Conference on Control and Automation. 2005. Budapest, Hungary.

[10] C. R. Reeves, Modern Heuristic Techniques for Combinatorial Problems. 1995, London: McGraw-Hill.

[11] J. S. Kim, Auto Tuning PID Controller Based on Improved Genetic Algorithm for Reverse Osmosis Plant. in Proceedings of the World Academy of Science and Engineering. 2008.

[12] F. Yin, J. Wang, and C. Guo, Design of PID Controllers Using Genetic Algorithms Approach for Low Damping Slow Response Plants,. Advances in Neural Networks, ed. L.N.i.C. Science. 2004: SpringerVerlag Berlin Heidelberg. 219-220. 
International Journal of $u-$ and e- Service, Science and Technology Vol.8, No. 6 (2015) 